\title{
Overall survival predictors in hepatocellular carcinoma patients treated with sorafenib
}

\author{
(D) Caroline Petersen da Costa Ferreira ${ }^{1}$ \\ (iD) Mauricio Alves Ribeiro ${ }^{1}$ \\ (iD) Luiz Arnaldo Szutan ${ }^{1}$
}

1. Departamento de Cirurgia, Irmandade da Santa Casa de Misericórdia de São Paulo. São Paulo, SP, Brasil

http://dx.doi.org/10.1590/1806-9282.66.3.275

\section{SUMMARY}

Malignant liver tumors are the fourth leading cause of cancer death worldwide. Hepatocellular carcinoma (HCC) accounts for 75-85\% of these. Most patients are diagnosed at incurable stages. Palliative care is the appropriate treatment course in these circumstances (chemoembolization and sorafenib). There are few national studies on sorafenib. The objective is to evaluate survival predictors of HCC patients treated with sorafenib and evaluate the compliance of its indication in relation to BCLC recommendations.

METHODS: A total of 88 patients with an indication of sorafenib from 2010 to 2017 at the ISCMSP were retrospectively analyzed. Univariate and multivariate analyzes were performed in the search for predictors of survival.

RESULTS: The mean age was 61.2 years, $70.5 \%$ were men, most were classified as Child-Pugh A (69.3\%), and BCLC C (94.3\%). Cirrhosis was present in $84.6 \%$ and portal hypertension in 55.7\%. Hepatitis C virus was the most common etiology (40.9\%). Sixty-nine (78.4\%) patients received the medication, with the average duration of treatment being 9.7 months. The mean overall survival was 16.8 months. Significant differences were observed in the multivariate analysis: ECOG PS ( $p=0.024)$ : Child-Pugh $(p=0.013)$, time of medication use $(p<0.001)$, clinical worsening $(p=0.031)$ and portal thrombosis $(p=0.010)$.

CONCLUSION: Absence of portal thrombosis, Child-Pugh A, longer time of medication use, ECOG PS O, and absence of suspension due to clinical worsening were predictors of better overall survival in the study. The drug's indication complies with BCLC guidelines in $94 \%$ of patients.

KEYWORDS: Liver neoplasms, hepatocellular carcinoma, sorafenib, protein kinase inhibitors.

\section{INTRODUCTION}

Malignant primary liver tumors are the fourth leading cause of cancer deaths worldwide. Hepatocellular carcinoma (HCC) is its main subtype, accounting for $75-85 \%$ of all primary liver tumors'.

Most patients with HCC receive a late diagno$\operatorname{sis}^{2,3}$. Patients in different situations such as multifocal lesions, locally advanced tumor, or comorbidities that limit curative treatment - surgical resection, transplant, radiofrequency ablation, or alcoholization - may only undergo palliative care.

Sorafenib (Nexavar ${ }^{\circledR}$, Bayer, German) is an oral multiple tyrosine kinase inhibitor, which acts both on tumor cells, inhibiting their proliferation, and on tumor vascular cells, inhibiting angiogenesis. It impedes the autophosphorylation of multiple receptors, such as vascular endothelial growth factor 
receptor 1,2,3, platelet-derived growth factor receptor $\beta$, stem cell factor receptor, RET proto-oncogene, fibroblast growth factor receptor 1, FMS-like tyrosine kinase 3 receptor and Ras/Raf MAPK intracellular pathways ${ }^{4,5}$.

The U.S. Food and Drug Administration approved this medication in 2007 for the treatment of advanced HCC based on two randomized clinical trials that demonstrated its safety and effectiveness ${ }^{6,7}$.

In Brasil, HCC's diagnosis is usually made in the intermediate and late phases ${ }^{8}$. Sorafenib is the only systemic therapy approved and in use by The Brazilian Unified Health System (Sistema Único de Saúde - SUS). Therefore, the analysis of non-interventional trial results is relevant, since the patient population is considerably different from the one used in randomized clinical trials - with their strict eligibility criteria. In addition, the assessment of these data is especially important to demonstrate the safety and effectiveness of Sorafenib in a real-life setting.

Thus, we proposed to study patients who had indication of Sorafenib, regardless they received the medication or not. This study sought to define predictors of overall survival (OS) with a more reliable view, in the clinical practice, in real conditions, out of the randomized clinical trial setting, and to assess the indication to treatment, according to the Barcelona Clinic Liver Cancer (BCLC) guidelines.

\section{METHODS}

This cross-sectional retrospective study included all patients with advanced hepatocellular carcinoma who received sorafenib treatment indication at Irmandade Santa Casa de São Paulo (ISCMSP) from January 2010 to November 2017. Patients were diagnosed histologically or imagiologically according to AASLD guidelines with advanced HCC. They kept sorafenib until radiological progression - according to guideline Response Evaluation Criteria In Solid Tumors modified- clinical worsening or unacceptable adverse effects. The decision to treat patients with sorafenib was been made under real-life practice conditions. Data were collected using case report forms.

Data on demographics, liver disease, Child-Pugh (CP) $)^{9,10}$, tumor-related, previous treatment, indication, receipt and suspension of the medication, alpha-fetoprotein levels (AFP), ECOG-PS ${ }^{11}$ (Eastern Cooperative Oncology Group-Performance Status), and BCLC ${ }^{12}$ classification were collected.

\section{Survival analysis}

Overall survival (OS) was measured from the date of indication of sorafenib until the date of death or end of follow-up (the last outpatient appointment). In patients who remained alive, the event was the final date of data collection (November 30, 2017).

\section{Statistical analysis}

The existence of associations between two categorical variables was evaluated using the Chi-Square test or Fisher's exact test. Patient survival was assessed by Kaplan-Meier curves, and groups were compared using the Log-Rank test (univariate analysis-UA). Multivariate analysis was performed using the Cox model. Due to the large number of variables, predictor variables were selected when their association with the dependent variable reached $10 \%$ significance in the univariate analysis (UA). Initially, all selected variables were included; then, variables not reaching $5 \%$ significance were excluded one by one in order of significance (backward method). All calculations were conducted using the statistical software IBM SPSS Statistics ${ }^{\circledR} 20.0$ and STATA ${ }^{\circledR} 12$. This study was approved by the Research Ethics Committee of the Faculty of Medical Sciences of ISCMSP, CAAE: 62130416.2.0000.5479

\section{RESULTS}

Eighty-eight patients were enrolled in this study. The mean age was 61.2 years [Standard Deviation (SD) $=13.0$ years], and the clinical and demographic characteristics are summarized in Table 1.

The presence of cirrhosis was common (86.4\%). The most common etiology was hepatitis C (40.9\%), followed by alcohol (33\%) and hepatitis B (15.9\%). Other causes were: NAFLD, Budd-Chiari, and autoimmune hepatitis. Alcohol consumption was the second risk factor in $28 \%$ of $\mathrm{HCV}$ patients, and $11.4 \%$ of HBV patients.

Regarding portal hypertension, 55.7\% of the patients had it, and $30.6 \%$ did not have it. Thirty patients (34.1\%) were completely healthy and asymptomatic (ECOG PS 0), but most of them already had some alteration in their performance status.

Vascular invasion and extrahepatic metastasis were found in $40.9 \%$ and $39.8 \%$ of the sample, respectively. The most common site of distant metastasis was the lung (17\%), followed by the bones (14.8\%). Other affected sites were: adrenal, peritoneum and 
retroperitoneum, subcutaneous cell tissue, and skin.

According to the Child-Pugh classification, 69.3\% and $30.7 \%$ of patients were A and B, respectively. Most of the sample, 94.3\%, were classified as BCLC $\mathrm{C}$ at the time of sorafenib treatment indication, and $44.3 \%$ had an indication of sorafenib after the failure of some locoregional treatment. Surgical resection and TACE were performed before sorafenib in 17 and 13 patients, respectively. Five patients had TACE after surgery, and one patient had alcoholization associated with the surgical procedure. Two transplant patients who had undergone TACE as a bridge therapy had a recurrence (distant metastasis) after

TABLE 1. CHARACTERISTICS OF PATIENTS WITH INDICATION OF SORAFENIB AT ISCMSP, N (\%)

\begin{tabular}{l|l} 
Characteristic & Percentage \\
\hline Male/ Female & $70.5 / 29,5$ \\
\hline $\begin{array}{l}\text { Etiology, HCV/ Alcohol/ HBV/ Other/ } \\
\text { Unknown }\end{array}$ & $40.9 / 33 / 15,9 / 6,8 / 9,1$ \\
\hline ECOG-PS, 0/1/2 & $34,1 / 47,7 / 18,2$ \\
\hline Child-Pugh, A/B & $69.3 / 30,7$ \\
\hline BCLC, B/C & $5,7 / 94,3$ \\
\hline Vascular invasion & 40.9 \\
\hline Extrahepatic metastasis & 39,8 \\
\hline Previous therapy, Surgery/ Transplant/ & $26,1 / 2,3 / 3,4 / 25$ \\
Alcoholization/ TACE & \\
\hline Portal hypertension, Yes/ No/ Absent data & $55,7 / 30,7 / 13,6$ \\
\hline Cirrhosis, Yes/No/ Absent data & $86,4 / 9,1 / 4,5$ \\
\hline Comorbidities, SH/CAD/ Prior Stroke/ & $36,4 / 9,1 / 3,4 / 8,0 / 30,7$ \\
DLP/Diabetes &
\end{tabular}

HCV: Hepatitis C virus. HBV: Hepatitis B virus. ECOG PS: Eastern Cooperative Oncology Group performance status; BCLC: Barcelona Clinic Liver Cancer Group; SH: Systemic hypertension; HF: Heart failure; CAD: Coronary artery disease; DLP: dyslipidemia; TACE- transarterial chemoembolization transplantation and, then, the indication of sorafenib. One patient underwent surgical resection, TACE, and alcoholization prior to sorafenib indication. Most patients (55.7\%) had an indication of sorafenib as the initial therapeutic modality.

\section{Administration of sorafenib}

Among 88 patients who had the medication prescribed, 69 received it, and 19 patients did not receive the treatment.

\section{Patients who received medication}

The mean OS time of sorafenib recipient patients was 16.8 months (95\% CI: 355.13 - 654.35 days). The mean time of sorafenib treatment duration was 9.7 months. Approximately $84 \%$ received the standard dose of $800 \mathrm{mg}$, and $13 \%$ received half the dose. There was no uniformity in the reasons for prescribing half the dose.

Among the 69 drug-recipient patients, almost 70\% had adverse effects (AE) described in the medical report. The main AEs were diarrhea (33\%), hand-foot syndrome (20.5\%), mucositis (11.4\%), fatigue (11.4\%), and nausea (11.4\%). Other AEs described were skin rash, anorexia, alopecia, thrombocytopenia, weight loss, itching, increased transaminases, cramp, increased blood pressure, insomnia, weight loss, sialorrhea, dyspepsia, and facial keratoacanthoma.

There was a $45 \%$ rate of medication suspension, with $48.4 \%$ of them for disease progression, $29 \%$ for clinical worsening, and $16.1 \%$ for AE. In $50.7 \%$ of the patients, the medication was maintained until the date of death.

TABLE 2. RESULTS OF THE INITIAL AND FINAL COX MULTIVARIATE REGRESSION MODELS

\begin{tabular}{|c|c|c|c|c|}
\hline & \multicolumn{2}{|l|}{ Initial Model } & \multicolumn{2}{|l|}{ Final Model } \\
\hline & Adjusted HR $(95 \% \mathrm{Cl})$ & $\mathrm{p}$ & Adjusted HR $(95 \% \mathrm{Cl})$ & $\mathrm{p}$ \\
\hline \multicolumn{5}{|l|}{ ECOG - PS } \\
\hline 1 & $2.57(1.22-5.43)$ & 0.013 & $2.18(1.11-4.32)$ & 0.024 \\
\hline 2 & $1.07(0.37-3.09)$ & 0.903 & $1.07(0.39-2.93)$ & 0.896 \\
\hline \multicolumn{5}{|l|}{$\mathrm{CP}$} \\
\hline B & $3.17(1.33-7.57)$ & 0.009 & $2.90(1.25-6.71)$ & 0.013 \\
\hline \multicolumn{5}{|l|}{ BCLC } \\
\hline B & $2.52(0.6-10.58)$ & 0.208 & - & - \\
\hline Treatment prior to sorafenib & $0.76(0.37-1.57)$ & 0.457 & - & - \\
\hline Time of medication use (days) & $0.996(0.994-0.998)$ & $<0.001$ & $0.996(0.994-0.998)$ & $<0.001$ \\
\hline Suspension due to clinical worsening & $2.67(1.13-6.31)$ & 0.025 & $2.55(1.09-5.96)$ & 0.031 \\
\hline Suspension due to side effect & $1.18(0.43-3.29)$ & 0.747 & - & - \\
\hline Portal Vein Thrombosis & $2.67(1.21-5.89)$ & 0.015 & $2.60(1.26-5.37)$ & 0.010 \\
\hline
\end{tabular}

Proportional risk test based on Schoenfeld residuals - Chi (6) = 3.44 - p=0.752. ECOG PS: Eastern Cooperative Oncology Group performance status; BCLC: Barcelona Clinic Liver Cancer Group; CP:Child-Pugh. 

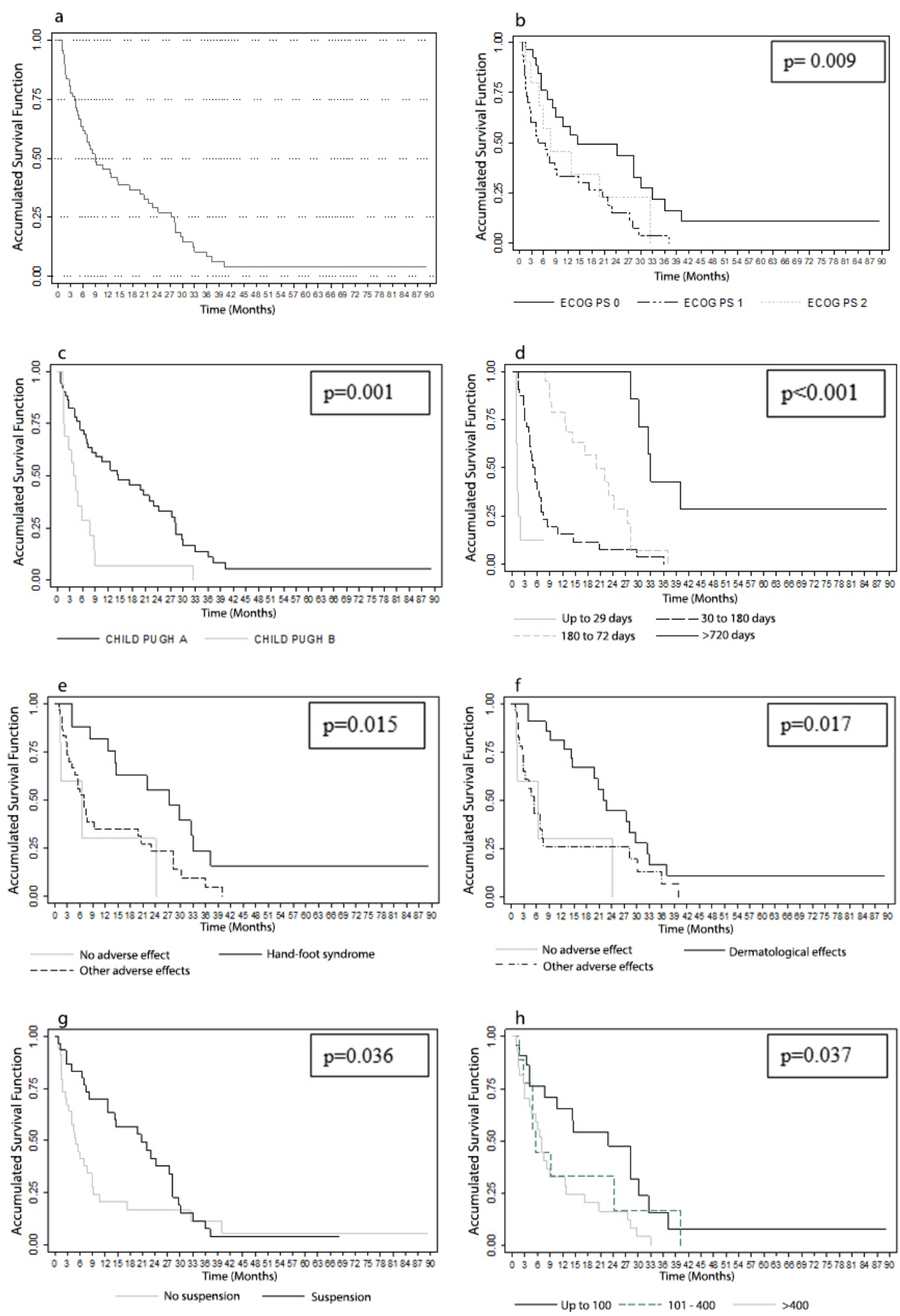

FIGURE 1.(A): GLOBAL SURVIVAL FUNCTION (SF) OF PATIENTS TREATED WITH SORAFENIB; (B): SF BY ECOG PS; (C): SF BY CP; (D): SF BY TIME OF USE OF MEDICATION; (E): SF BY AE -HAND AND FOOT SYNDROME; (F): SF BY AE DERMATOLOGICAL EFFECTS; (G): SF BY MEDICAL SUSPENTION; (H) SF BY AFP

Patients' survivals by categorical characteristics were analyzed also by Kaplan-Meier models. Figure 1 shows the functions of accumulated survival due to the variables that proved to be significant.
Table 2 shows the Cox regression model, with the variables $10 \%$ significant in UA. Variables associated with AE- Hand-foot syndrome and AE-dermatological effects and AFP were not considered due to the high 


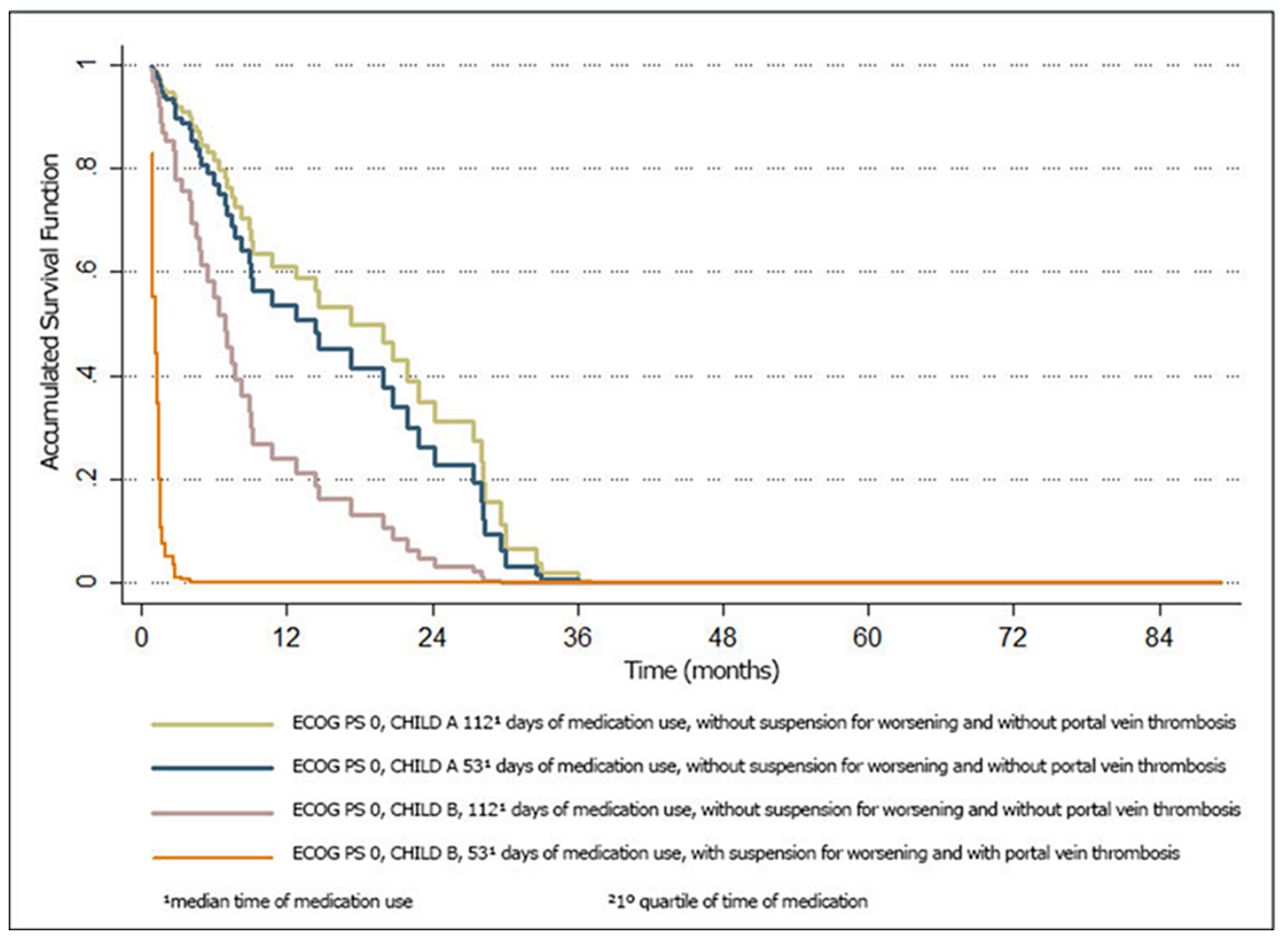

FIGURE 2. SURVIVAL FUNCTIONS ESTIMATED VIA FINAL COX MODEL FOR SOME PATIENT PROFILES

number of cases with missing information (16 cases (23.2\%) and 9 cases (13.0\%), respectively for adverse events and AFP. By including these two variables, the model estimation was not possible.)

According to table 2, the following variables remained significant in the final model: ECOG PS, Child-Pugh (CP), time of medication use, suspension - clinical worsening, and portal vein thrombosis.

Figure 2 presents the estimates of the survival functions of the final Cox model for some patients' profiles.

\section{Survival by medication}

A survival rate comparison was drawn between drug recipients and non-recipients (Figure 3).

It was observed that patients without medication had lower survival than patients receiving medication ( $p<0.001)$. The median overall survival time in the group of non-recipient patients was 69.95 days. (95\% CI: 46.12 - 93.78), about 2.3 months.

\section{DISCUSSION}

Of the 88 patients with an indication for the medication, 78 (4\%) received sorafenib, but $21.6 \%$ did not receive the medication despite having the indication; patients died before the medication was available by the State Secretariat of Health or lost eligibility during the wait for medication.
Sorafenib is released by SES (Secretaria Estadual de Saúde) for patients after medical indication. The documentation comes from the ISCMSP central pharmacy and is sent to SES. As soon as the SES bureaucratic process is completed and the medication dispensed, a telegram is sent to the patient's residence, who can then retrieve the drug from the SES building. The mean time between indication and reception of medication was $32.53(\mathrm{SD}=7.86)$, and the median was 27.5 days.

The mean time of therapy with sorafenib was 9.7 months, a similar value was presented in another Brazilian study (8.23 months) ${ }^{13}$. In general, the meantime of overall survival was 504.74 days (95\% CI: 355.13 654.35), around 16.8 months, higher than in previous studies such as the SHARP (10.7 months) and Asia-Pacific (6.5 months) $)^{6,7}$.

A recent French study established a new scoring system for BCLC C stratification using five independent prognostic elements: CP, performance status, AFP levels, number of nodules, and infiltrative nature of the tumor ${ }^{14}$.

Another Korean study proposed establishing the sub-classification of stage $C$ into three groups according to the scores established by five prognostic factors (CP, AFP, type of tumor (nodular versus diffuse/ infiltrative), extrahepatic metastasis and portal invasion): low-risk, medium-risk and high-risk group, with 


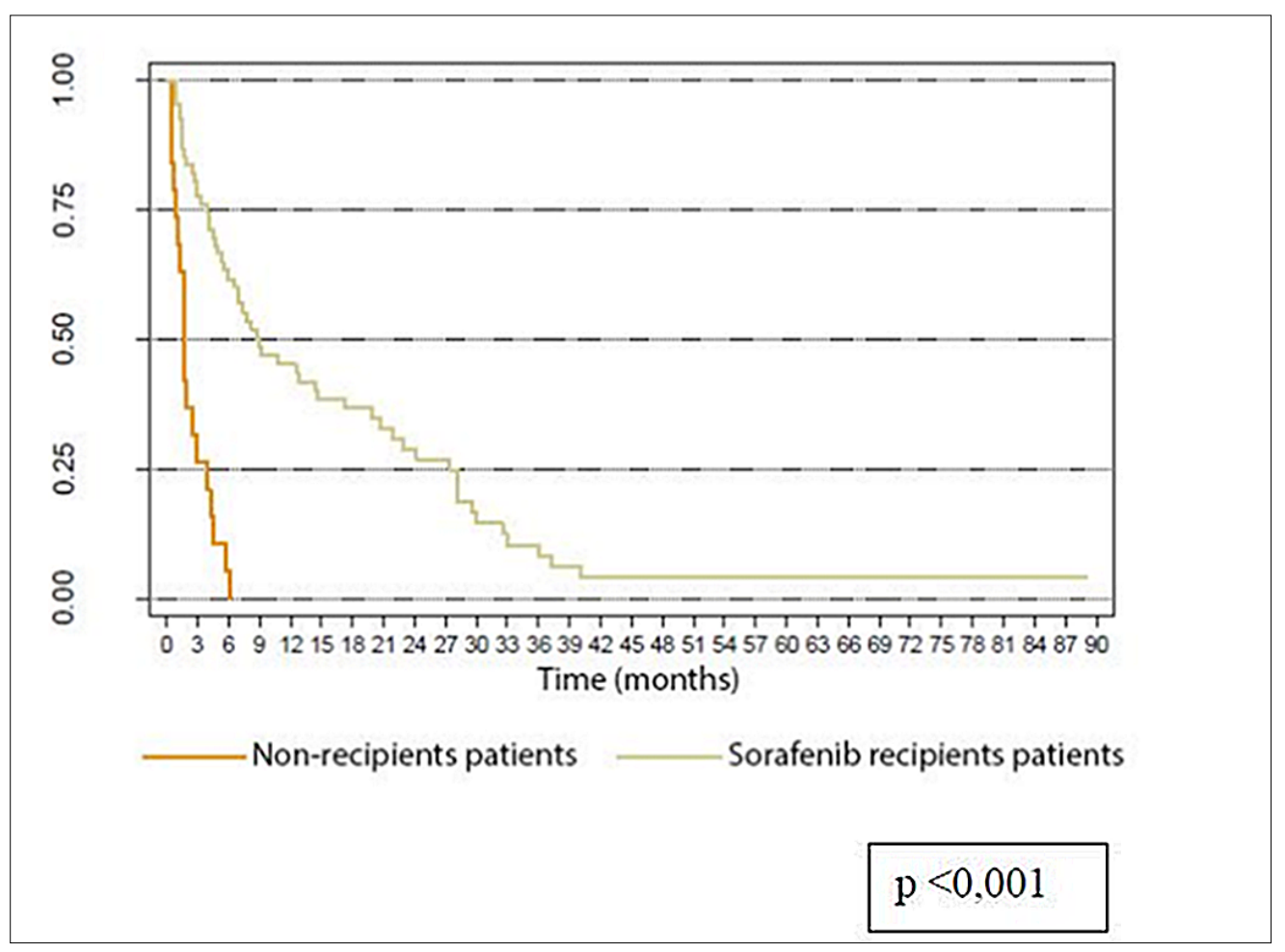

FIGURE 3.

KAPLAN - MEIER

ACCUMULATED

SURVIVAL FUNCTION

BY USE OF

MEDICATION expected survival of 16.7 months, 9.6 months, and 4.5 months, respectively, in ECOG PS 0 and $1^{14}$.

Although the BCLC algorithm for HCC treatment includes only advanced BCLC C hepatocellular carcinoma, early or intermediate HCC with contraindication for loco-regional treatment, and intermediate HCC with progressive disease post-TACE (without indication of new TACE) are also indications for this drug. In real-life observational studies, patients who use sorafenib are not always BCLC C $\mathrm{C}^{13,15,16}$.

Due to the high number of cases without information on the AFP value and presence of adverse effects, it was not possible to create a mathematical formula that estimates the survival time. It was only possible to estimate survival functions through the final Cox model for some patients' profiles.

In the multivariate analysis, the variables portal vein thrombosis $(\mathrm{p}=0.010)$, Child-Pugh $(\mathrm{p}=0.013)$, time of medication use $(p<0.001)$, ECOG PS $(p=0.024)$, and suspension for clinical worsening $(p=0.031)$, remained statistically significant.

There was no statistically significant difference in overall survival between patients using sorafenib alone (advanced-stage diagnosis - BCLC C) and patients with previous therapy (early or intermediate stage diagnosis), despite a tendency for better survival in the group that had received another type of therapy previously (p: 0.067).
In our study, patients with vascular thrombosis had a risk 2.6 times higher of death than those without thrombosis. In the sub-analysis of the study SHARP, worse overall survival (8.1 versus 14.1 months) and lower time of disease progression (4.1 versus 7.3 months) were identified in the presence of vascular invasion, while in the presence of extrahepatic metastases, they identified worse overall survival (8.9 versus 14.1 months), with similar time of disease progression (5.3 versus 5.8 months) $)^{17}$.

The presence of extrahepatic metastases had no statistical significance in our casuistry concerning OS; however, it is imperative to observe that lymph node metastases (38 patients) were quantified separately from distant metastases (35 patients), which may justify the non-significance.

Alencar et al. ${ }^{13}$, in 2016, identified three variables associated with better OS: treatment duration longer than 6 months, presence of dermatological adverse effects, and AFP value lower than $100 \mathrm{ng} / \mathrm{ml}$.

In our study, Child-Pugh was considered a predictor variable of a better OS, as well as in other studies ${ }^{13,18}$. Patients with CP B had a risk 2.9 times higher of death than those with CP A. The GIDEON study ${ }^{15}$ found a mean survival of 13.6 months for Child A patients as compared to 5.2 in Child B patients, while Hollebecque et al. ${ }^{16}$ found 13 versus 4.5 months, and Iavarone et al. ${ }^{19}$ had 12.7 versus 7.7 months, respectively. 
Still in the GIDEON study ${ }^{15}$, a significant part of the patients could maintain sorafenib for more than 28 weeks, including $21 \%$ of patients with CP B, suggesting that those who can keep the treatment besides the initial period are able to continue subsequently for long periods, reinforcing the importance of the management of adverse effects in the first weeks of treatment. In our study, for every additional day of medication use, a $0.4 \%$ reduction in the risk of death was observed.

Similarly, a positive association between treatment duration and OS in the trials of Hsaio et al. ${ }^{20}$ and Arizumi et al. ${ }^{21}$ was also verified, which magnifies the importance of the duration of treatment with sorafenib.

Similarly to the results obtained for the CP scale $(p=0.013)$, the functional status $(p=0.024)$ showed a strong association with OS. Patients with ECOG PS 1 have a risk of death 2.18 times higher than those with ECOG PS O, adjusted by the other variables of the final model. In the study INSIGHT ${ }^{22}$, the baseline performance status had a significant effect on overall survival, with survival curves distinguishable for ECOG $0,1,2$, and $3(\mathrm{p}<0.0001)$.

The serum AFP levels were stratified in values up to 100 , from 101 to 400 , and higher than $400 \mathrm{ng} / \mathrm{ml}$. The value of 400 was used because it was the value informed in the medical report for the assessment of the request of oncological drugs of SES. Relative to the other subgroups, a Brazilian trial with the analysis of survival in patients with hepatocellular carcinoma who received sorafenib identified AFP values $<100 n g /$ $\mathrm{ml}$ as a possible predictor of better OS..$^{13}$

The correlation between the presence of dermatological adverse effects and time to disease progression and overall survival has been suggested in some retrospective trials with patients with HCC undergoing treatment with sorafenib ${ }^{18,23}$ and validated in prospective study ${ }^{24}$.

With regard to treatment interruption with the suspension of sorafenib, the reasons in our casuistry were: disease progression, clinical worsening, and the presence of important adverse effects.

In $45 \%$, therapy with sorafenib was suspended. In these patients, radiological disease progression - according to the guideline Response Evaluation Criteria In Solid Tumors modified (RECISTm) - was the most common cause of discontinuation (48.4\%). In the multivariate analysis, patients who had the medication suspended for clinical worsening had a risk of death 2.55 times higher than those without such condition.

Initial doses of sorafenib vary widely between countries. In the GIDEON study ${ }^{15}$, in the Korean and Japanese arms, respectively, $67 \%$ and $45.5 \%$ of the patients received the standard dose $800 \mathrm{mg} /$ day initially. Although some authors suggest starting with half the dose to prevent the development of side effects, this approach is not a consensus. Reig believes that the low-dose onset strategy to increase tolerance may not trigger the mechanism associated with the development of dermatological adverse events with the associated loss of survival improvement ${ }^{24}$.

An interesting feature addressed in this study was that all patients who had an indication for sorafenib treatment were evaluated regardless they received the drug or not. Despite not having the statistical value of Intention to Treat (a statistical concept used in randomized control studies where patients are analyzed with the group that was previously randomized), it is worth noting that about $20 \%$ of patients who have medical indication of sorafenib -and prescription- do not receive treatment.

Due to its observational character, this study is limited for data analysis for several reasons, which include: the absence of a control group, selection bias, and limited data from medical reports many times not completed carefully. However, a non-interventionist trial creates space for observing the actual clinical practice, identifying the most critical points in the daily assessment of patients.

The proportion of missing data was $4.5 \%$ in relation to the presence of cirrhosis, $13 \%$ regarding AFP value, $13.6 \%$ for portal hypertension, $23 \%$ for the presence or absence of adverse effects, and $7.2 \%$ in relation to the suspension or continuation of the medication.

From this study, it was possible to assess our results, and in an indirect manner, the quality of the care provided, showing the need for better training of resident physicians and assistant physicians in order to make a better management of these patients possible, which may implicate better results.

\section{CONCLUSIONS}

With regard to the results obtained in the treatment of the patients included in this study, we can conclude that the absence of portal vein thrombosis, Child-Pugh A, ECOG PS 0, longer time of medication use, and absence of suspension for clinical worsening 
are predictor factors of better overall survival. The indication of the medication is in accordance with the BCLC recommendations in $94 \%$ of the patients.

\section{Abbreviation List}

AASLD: Associação Americana do Estudo das doenças hepáticas

AE: Adverse effects

AFP: Alpha-fetoprotein

BCLC: Barcelona Clinic Liver Cancer Group

ECOG-PS: Eastern Cooperative Oncology

Group-Performance Status

HCC: Hepatocellular carcinoma

ISCMSP: Irmandade da Santa Casa de Misericórdia de São Paulo

OS: Overall survival

SD: Standard Deviation
SUS: Sistema Único de Saúde

UA: Univariate analysis

\section{Acknowledgment}

We would like to thank the patients, the Department of Surgery of ISCMSP, and the Secretaria de Saúde of São Paulo for their assistance in the development of this work. We would also like to thank Tiane for all the hard work and dedication

\section{Author's contribution}

Ferreira CPC performed the research, analyzed the data and wrote the paper. Ribeiro MA conceived the original idea and contributed to the interpretation of the results. Szutan LA guided and reviewed the research. All authors provided critical feedback and contributed to the final manuscript.

\section{RESUMO}

Tumores malignos do fígado são a quarta maior causa de morte por câncer, sendo que o carcinoma hepatocelular (CHC) corresponde a 85-90\% desses casos. A maioria dos doentes apresenta-se, ao diagnóstico, sem possibilidade de tratamento curativo, restando apenas as opções paliativas (quimioembolização e sorafenibe). Há poucos estudos nacionais acerca do sorafenibe.

OBIETIVO: Avaliar fatores preditivos de sobrevida em pacientes com CHC que tiveram indicação de tratamento com sorafenibe na Irmandade da Santa Casa de Misericórdia de São Paulo (ISCMSP) e avaliação da conformidade da indicação da medicação em relação às recomendações do BCLC.

MÉTODOS: Foram analisados retrospectivamente os dados de 88 pacientes que tiveram indicação de tratamento com sorafenibe no período de 2010 a 2017 na ISCMSP. Análises univariada e multivariada foram realizadas na busca de preditores de sobrevida global nos pacientes que receberam a medicação.

RESULTADOS: Idade média de 61,2 anos, sendo 70,5\% homens. A maioria (69,3\%) foi classificada como Child Pugh A e BCLC C (94,3\%). A cirrose esteve presente em $84,6 \%$ e a hipertensão portal em $55,7 \%$ desses. O vírus da hepatite C foi a etiologia mais comum (40,9\%) do CHC. Sessenta e nove (78,4\%) pacientes receberam a medicação, sendo o tempo médio de duração do tratamento 9,7 meses e a sobrevida global média, 16,8 meses. Diferenças significativas foram observadas na análise multivariada: $E \operatorname{cog} P S(p=0,024), C P(p=0,013)$, tempo de uso de medicação $(p<0,001)$, suspensão por piora clínica $(p=0,031)$ e trombose portal $(p=0,010)$.

CONCLUSÃo: Ausência de trombose portal, Child Pugh A, Ecog PS 0, tempo maior de uso de medicação e ausência de suspensão por piora clínica foram fatores preditores de melhor sobrevida global e a indicação da medicação esteve em conformidade com as orientações do BCLC em $94 \%$ dos pacientes.

PALAVRAS-CHAVE: Neoplasias hepáticas. Carcinoma hepatocelular. Sorafenibe. Inibidores de proteínas quinases.

\section{REFERENCES}

1. Bray F, Ferlay J, Soerjomataram I, Siegel RL, Torre LA, Jemal A. Global cancer statistics 2018 : GLOBOCAN estimates of incidence and mortality worldwide for 36 cancers in 185 countries. 2018;68(6):394-424.

2. Yang ID, Mohamed EA, Aziz AOA, Shousha HI, Hashem MB, Nabeel MM, et al; Africa Network for Gastrointestinal and Liver Diseases. Characteristics, management, and outcomes of patients with hepatocellular carcinoma in Africa: a multicountry observational study from the Africa Liver Cancer Consortium. Lancet Gastroenterol Hepatol. 2017;2(2):103-11.

3. Debes JD, Chan AJ, Balderramo D, Kikuchi L, Gonzalez Ballerga E, Prieto JE, et al. Hepatocellular carcinoma in South America: evaluation of risk factors, demographics and therapy. Liver Int. 2018;38(1):136-43.

4. Wilhelm SM, Adnane L, Newell P, Villanueva A, Llovet JM, Lynch M. Preclinical overview of sorafenib, a multikinase inhibitor that targets both Raf and VEGF and PDGF receptor tyrosine kinase signaling. Mol Cancer Ther. 2008;7(10):3129-40.

5. Gong L, Giacomini MM, Giacomini C, Maitland ML, Altman RB, Klein TE. PharmGKB summary: sorafenib pathways. Pharmacogenet Genomics. 2017;27(6):240-6

6. Llovet I, Ricci S, Mazzaferro V, Hilgard P, Gane E, Blanc JF, et al; SHARP Investigators Study Group. Sorafenib in advanced hepatocellular carcinoma. Engl | Med. 2008;359(4):378-90

7. Cheng AL, Kang YK, Chen Z, Tsao C), Qin S, Kim JS, et al. Efficacy and safety of sorafenib in patients in the Asia-Pacific region with advanced hepatocellular carcinoma: a phase III randomised, double-blind, placebo-controlled trial. Lancet Oncol. 2009;10(1):25-34.

8. Kikuchi L, Chagas AL, Alencar RS, Paranaguá-Vezozzo DC, Carrilho FJ 
Clinical and epidemiological aspects of hepatocellular carcinoma in Brasil. Antivir Ther. 2013;18(3 Pt B):445-9.

9. Pugh RN, Murray-Lyon IM, Dawson JL, Pietroni MC, Williams R. Transection of the oesophagus for bleeding oesophageal varices. Br J Surg. 1973;60(8):646-9.

10. Child CG. The liver and portal hypertension. Philadelphia: Saunders; 1964.

11. Oken MM, Creech RH, Tormey DC, Horton J, Davis TE, McFadden ET, et al. Toxicity and response criteria of the Eastern Cooperative Oncology Group. Am J Clin Oncol. 1982;5(6):649-55.

12. Bruix J, Sherman M; American Association for the Study of Liver Diseases. Management of hepatocellular carcinoma: an update. Hepatology. 2011;53(3):1020-2

13. Alencar RSSM, Kikuchi L, Tani CM, Chagas AL, Camargo CC, Pfiffer TEF, et al. Better management of adverse events favors sorafenib treatment of HCC patients and impact on survival. J Cancer Ther. 2016;7:275-84.

14. Yoo JJ, Chung GE, Lee JH, Nam JY, Chang Y, Lee JM, et al. Sub-classification of advance-stage hepatocellular carcinoma: a cohort study including 612 patients treated with sorafenib. Cancer Res Treat. 2017;50(2):366-73.

15. Marrero IA, Kudo M, Venook AP, Ye SL, Bronowicki IP, Chen XP, et al. Observational registry of sorafenib use in clinical practice across ChildPugh subgroups: the GIDEON study. J Hepatol. 2016;65(6):1140-7.

16. Hollebecque A, Cattan S, Romano O, Sergent G, Mourad A, Louvet A, et al. Safety and efficacy of sorafenib in hepatocellular carcinoma: the impact of the Child-Pugh score. Aliment Pharmacol Ther. 2011;34(10):1193-201.
17. Bruix J, Raoul JL, Sherman M, Mazzaferro V, Bolondi L, Craxi A, et al. Efficacy and safety of sorafenib in patients with advanced hepatocellular carcinoma: subanalyses of a phase III trial. J Hepatol. 2012;57(4):821-9.

18. Otsuka T, Eguchi Y, Kawazoe S, Yanagita K, Ario K, Kitahara K, et al. Skin toxicities and survival in advanced hepatocellular carcinoma patients treated with sorafenib. Hepatol Res. 2012;42(9):879-86.

19. lavarone M, Cabibbo G, Piscaglia F, Zavaglia C, Grieco A, Villa E, et al. Field-practice study of sorafenib therapy for hepatocellular carcinoma: a prospective multicenter study in Italy. Hepatology. 2011;54(6):2055-63.

20. Hsiao WD, Peng CY, Chuang PH, Lai HC, Cheng KS, Chou JW, et al. Evaluation of dose-efficacy of sorafenib and effect of transarterial chemoembolization in hepatocellular carcinoma patients: a retrospective study. BMC Gastroenterol. 2016:16:50

21. Arizumi T, Ueshima K, Iwanishi M, Chishina H, Kono M, Takita M, et al. Reallife clinical practice with sorafenib in advanced hepatocellular carcinoma: a single-center experience second analysis. Dig Dis. 2015;33(6):728-34.

22. Ganten TM, Stauber RE, Schott E, Malfertheiner P, Buder R, Galle PR, et al. Sorafenib in patients with hepatocellular carcinoma-results of the observational INSIGHT study. Clin Cancer Res. 2017;23(19):5720-8.

23. Vincenzi B, Santini D, Russo A, Addeo R, Giuliani F, Montella L, et al. Early skin toxicity as a predictive factor for tumor control in hepatocellular carcinoma patients treated with sorafenib. Oncologist. 2010;15(1):85-92.

24. Reig M, Torres F, Rodriguez-Lope C, Forner A, Llarch N, Rimola J, et al. Early dermatologic adverse events predict better outcome in HCC patients treated with sorafenib. | Hepatol. 2014;61(2):318-24. 